\title{
The Heat-Transfer Performance of Gas-Solid Trickle Flow over a Regularly Stacked Packing
}

\author{
A. B. VERVER* and W. P. M. VAN SWAAIJ \\ Department of Chemical Technology, Twente University of Technology, P.O. Box 217, 7500 AE Enschede (The \\ Netherlands) \\ (Received August 10,1984; in revised form September 9, 1985)
}

\section{SUMMARY}

The heat-transfer behaviour of a countercurrent gas-solid trickle flow contactor is studied, using coarse sand particles as the solids phase. Experimental data on the overall heat-transfer rate constant between the gas flow and the solid particle flow were obtained in a $0.15 \mathrm{~m}$ square cross-section column packed with regularly stacked packing elements specially developed for dilute countercurrent gas-solid contactors. Pressure drop over these packings is low, while countercurrent heat-transfer properties are remarkable; for $0.5 \mathrm{~m}$ of packing, the number of transfer units may amount to about 2 to 4 , depending on the gas and solids mass flow rates and the packing construction used. Therefore, the present contactor might be attractive for application as a heat exchanger.

The pressure drop caused by the solids flow and the heat-transfer rate constant show very similar behaviour and at low solids mass fluxes their values agree with the data obtained from the single-particle flow model described in a previous paper [1]. Heattransfer behaviour is described reasonably well by a model based on single-particle flow and by incorporating the effect of particle agglomeration at higher solids fluxes.

\section{INTRODUCTION}

Trickle flow of solids over a packing countercurrently to a gas flow is receiving increasing attention as an operation mode for

*Present address: Akzo Engineering b.v., P.O. Box $209,6800 \mathrm{LV}$ Arnhem (The Netherlands) the countercurrent contacting of particulate solids and a gas, especially in the field of fuel gas or flue gas treatment, in which the relatively low pressure drop is an attractive advantage. Applications can be in mass- or heattransfer processes and also in chemical reactors. In a preceding article [1], we described the hydrodynamic properties of trickle flow of several types of solid particles over a specially designed, regularly stacked column packing. In a subsequent investigation, the heat-transfer performance described in the present paper was studied.

The interfacial transfer properties of gassolid trickle flow have been studied by Roes [2], using fluid cracking catalyst (FCC) particles and a packed column of Pall rings. By means of adsorption experiments with a strongly adsorbing Freon tracer, the overall mass-transfer rate constant has been determined [3]. The actual interfacial mass-transfer rate constant was then evaluated by taking account of axial mixing in both phases, which was determined separately by residence time distribution experiments. Due to the presence of the packing, the effect of axial mixing on countercurrent mass-transfer performance was reduced, whereas the interfacial mass-transfer rate was found to be high. For a packing of $15 \mathrm{~mm}$ Pall rings, the height of an overall mass-transfer unit amounted typically to about $0.16 \mathrm{~m}$ [3]. Similar results on mass transfer have been obtained in a zigzag column [4], again using FCC particles.

Trickle flow of particulate solids might also be attractive in the field of gas-solid heat exchange [5]. From the patent literature [6], solids-preheating devices are known which are similar to the packed column studied by Roes [2]. Such a raining packed-bed heat 
exchanger has been investigated by Large et al. [7]. It was found that the thermal performance of a Pall rings packing was not significantly improved by an increase in the bed height and that the efficiency depends strongly on the initial solids distribution [8]. The explanation could be wall flow of solids or channeling of solids due to insufficient radial distribution properties of the packing.

The essential role of a packing can be derived from studies on heat exchange between a gas flow and a dilute flow of particles in the absence of a packing, in the so-called falling-cloud heat exchanger [9]. Here, solid particles are sprayed into a vertical empty duct in which hot stack gases are flowing countercurrently to the downward flowing particles. Proper radial distribution of the gas flow [9] and effective initial distribution of solid particles over the cross-section of the column [10] are difficult to achieve in such an apparatus.

In our investigation, therefore, much attention has been paid to the packing geometry. On the basis of visual observations of the solids flow in preliminary tests with transparent stacked packings, we developed two regularly stacked packing constructions producing a rapid radial solids distribution throughout the column and preventing wall flow of solids. One of these packings was also used previously in studies on the hydrodynamic behaviour of gas-solid trickle flow [1]. In the experiments on thermal performance of such packings, the solids mass flux was relatively low, so as to obtain gas-to-solids mass flux ratios most favourable for countercurrent heat exchange, i.e., between 0.5 and 2.0. To permit high gas velocities, coarse sand particles were used as the solids phase. A comparison between the results of the two packing constructions is made with regard to pressure-drop and heat-transfer efficiency. For an evaluation of the heat-transfer properties, we used a numerical calculation procedure in which heat losses to the surroundings and the temperature dependency of thermal properties are taken into account.

\section{THEORY}

The performance of a countercurrent mass or heat exchanger is usually expressed by the number of overall transfer units, NTU. It depends on the number of true transfer units, determined by the interfacial transfer rate, and the number of dispersion units, determined by the axial dispersion in both phases. The influence of axial dispersion will be discussed later. When axial mixing has a negligible effect, for constant thermal properties of gas and solids and a constant heat-transfer rate constant, $\mathrm{NTU}_{\mathrm{g}}$ follows from the logarithmic mean temperature difference of the gas and solids phase:

$$
\begin{aligned}
\mathrm{NTU}_{\mathrm{g}}= & \frac{\left|\Delta T_{\mathrm{g}}\right|}{\left(T_{\mathrm{g}, \text { out }}-T_{\mathrm{s}, \text { in }}\right)-\left(T_{\mathrm{g}, \text { in }}-T_{\mathrm{s}, \text { out }}\right)} \\
& \times \ln \left(\frac{T_{\mathrm{g}, \text { out }}-T_{\mathrm{s}, \text { in }}}{T_{\mathrm{g}, \text { in }}-T_{\mathrm{s}, \text { out }}}\right) \\
& \quad \text { where }\left|\Delta T_{\mathrm{g}}\right| \neq T_{\mathrm{s}, \text { out }}-T_{\mathrm{s}, \text { in }}
\end{aligned}
$$

where $\Delta T_{\mathrm{g}}$ is the temperature change of the gas phase. However, the above simplifications are not always realistic, as the thermal properties of the gas and particularly those of the solids (sand) may change substantially with temperature. Moreover, heat losses to the surroundings might not be negligible. From the heat balance over each phase, the following differential equations are obtained:

Gas phase:

$$
\begin{aligned}
& \left.G C_{\mathrm{p}, \mathrm{g}}\left(T_{\mathrm{g}}\right) \frac{\mathrm{d} T_{\mathrm{g}}}{\mathrm{d} x}+(\alpha a) T_{\mathrm{g}}-T_{\mathrm{s}}\right) \\
& +U_{\mathrm{L}} a_{\mathrm{L}}\left(T_{\mathrm{g}}-T_{0}\right)=0
\end{aligned}
$$

Solids phase:

$$
S C_{\mathrm{p}, \mathrm{s}}\left(T_{\mathrm{s}}\right) \frac{\mathrm{d} T_{\mathrm{s}}}{\mathrm{d} x}+\alpha a\left(T_{\mathrm{g}}-T_{\mathrm{s}}\right)=0
$$

where $U_{\mathrm{L}} a_{\mathrm{L}}$ is the overall heat-transfer rate constant for heat loss. The heat-transfer rate constants $\alpha a$ and $U_{\mathrm{L}} a_{\mathrm{L}}$ are assumed to be independent of temperature and constant throughout the column. Then, from the experimentally determined inlet and outlet temperatures, the heat-transfer rate constant $\alpha a$ can be derived by numerical calculation, provided that $U_{\mathrm{L}} a_{\mathrm{L}}$ is known. The column is divided into a number of sections, $n$, in which temperatures and thermal properties of both phases are approximately constant (see 


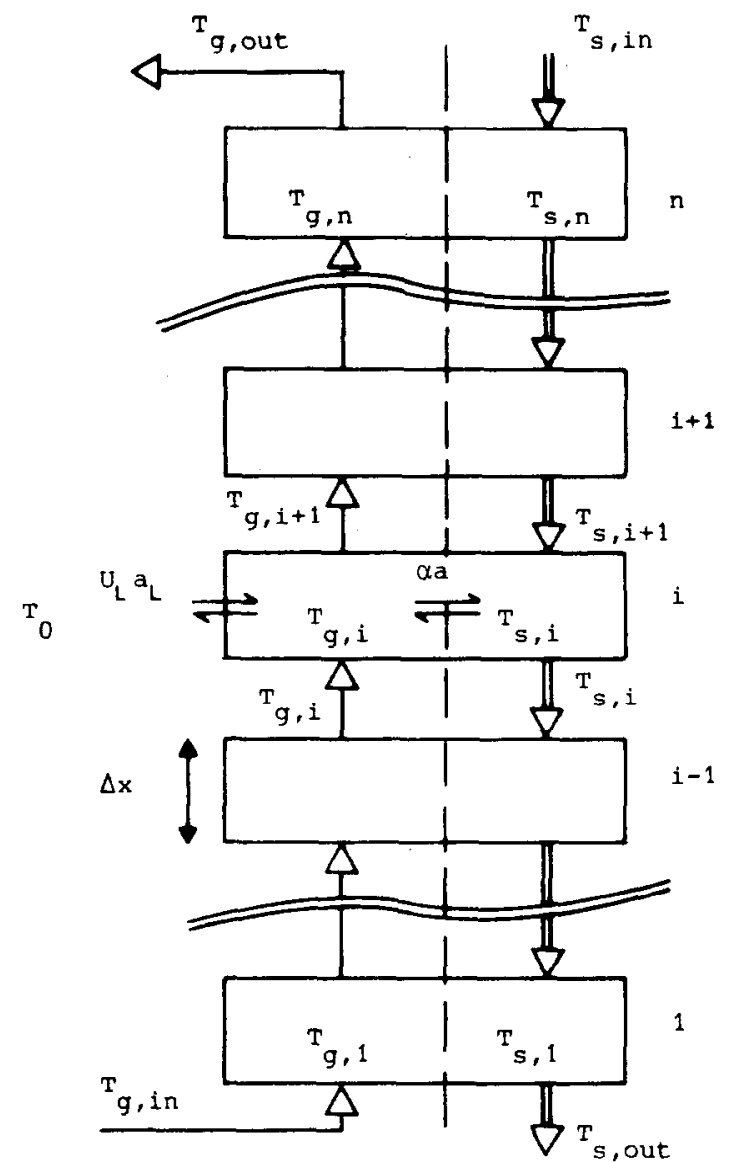

Fig. 1. Model for numerical calculation of heattransfer rate constant.

Fig. 1). Rewriting the differential equations above, we obtain for each section of length $\Delta x(=L / n)$ the following temperature equations:

$$
\begin{aligned}
T_{\mathrm{g}, i+1}= & T_{\mathrm{g}, i}-\frac{(\alpha a) \Delta x}{G C_{\mathrm{p}, \mathrm{g}} T_{\mathrm{g}, i}}\left(T_{\mathrm{g}, i}-T_{\mathrm{s}, i}\right) \\
& -\frac{U_{\mathrm{L}} a_{\mathrm{L}} \Delta x}{G C_{\mathrm{p}, \mathrm{g}} T_{\mathrm{g}, i}}\left(T_{\mathrm{g}, i}-T_{0}\right) \\
T_{\mathrm{s}, i+1}= & T_{\mathrm{s}, i}-\frac{(\alpha a) \Delta x}{S C_{\mathrm{p}, \mathrm{s}} T_{\mathrm{s}, i}}\left(T_{\mathrm{g}, i}-T_{\mathrm{s}, i}\right)
\end{aligned}
$$

Now, a straightforward calculation method is obtained, as $T_{\mathrm{g}, 1}$ and $T_{\mathrm{s}, 1}$ are equal to $T_{\mathrm{g}, \text { in }}$ and $T_{\mathrm{s} \text {, out }}$ respectively. The value of $\alpha a$ has to be adjusted until either $T_{\mathrm{g}, n}=T_{\mathrm{g}, \text { out }}$ or $T_{\mathrm{s}, n}=$ $T_{\mathrm{s} \text {, in }}$. The heat-loss rate constant $U_{\mathrm{L}} a_{\mathrm{L}}$ is easily estimated from the temperature drop over the column when solids flow is absent, i.e., $T_{\mathrm{g} \text {, out }} \approx T_{\mathrm{g}, \text { in }}$ :
$U_{\mathrm{L}} a_{\mathrm{L}}=\frac{G C_{\mathrm{p}, \mathrm{g}} T_{\mathrm{g}, \text { in }}}{L} \ln \left(\frac{T_{\mathrm{g}, \text { in }}-T_{0}}{T_{\mathrm{g}, \text { out }}-T_{0}}\right)$ where

$S=0$

The number of overall transfer units $\mathrm{NTU}_{\mathrm{g}}$ is obtained from the value of $\alpha a$ by the definition of $\mathrm{NTU}_{\mathrm{g}}$, in the case of negligible influence of axial dispersion:

$$
\begin{aligned}
\mathrm{NTU}_{\mathrm{g}} & =\frac{L}{\mathrm{HTU}} \\
& =\frac{\alpha a}{G \bar{C}_{\mathrm{p}, \mathrm{g}}} L
\end{aligned}
$$

\section{EXPERIMENTS}

The experiments were carried out in two gas-solid trickle flow contactors in series, forming an overall countercurrent gas-to-gas heat exchanger (Fig. 2). Thermal performance was monitored on the upper column, into which preheated air was blown. A continuous flow of sand particles was introduced via a small fluid bed on top of the upper column, serving as a gas seal, and was distributed uniformly over the cross-section of the column by means of four downcomers. The cross-sectional area of the packed column was $0.15 \mathrm{~m} \times 0.15 \mathrm{~m}$ and the packing height was $0.48 \mathrm{~m}$. The apparatus was insulated by a layer of alumina fibres of about $0.09 \mathrm{~m}$ thickness. The column packing construction consisted of a bank of stacked tubes of square cross-section $(20 \mathrm{~mm} \times 20 \mathrm{~mm}), c f$. [1], or, alternatively, it was made of angular metal strips stacked in a regular pattern (see Fig. 3).

Air was preheated by an in-line heating element and was fed to the upper column via a perforated plate distributor, $c f$. [1]. Below the gas distributor, the particles leaving the packed column were collected and transported to the lower column via a small fluid bed seal. At the outlet of the lower column, the particles flowed into an air-fluidized storage vessel, from which they were recycled to the top of the upper column by means of an air-blown pneumatic conveying line.

The air flow rate to the column was adjusted and measured by calibrated flowmeters. The solids flow rate was controlled by 


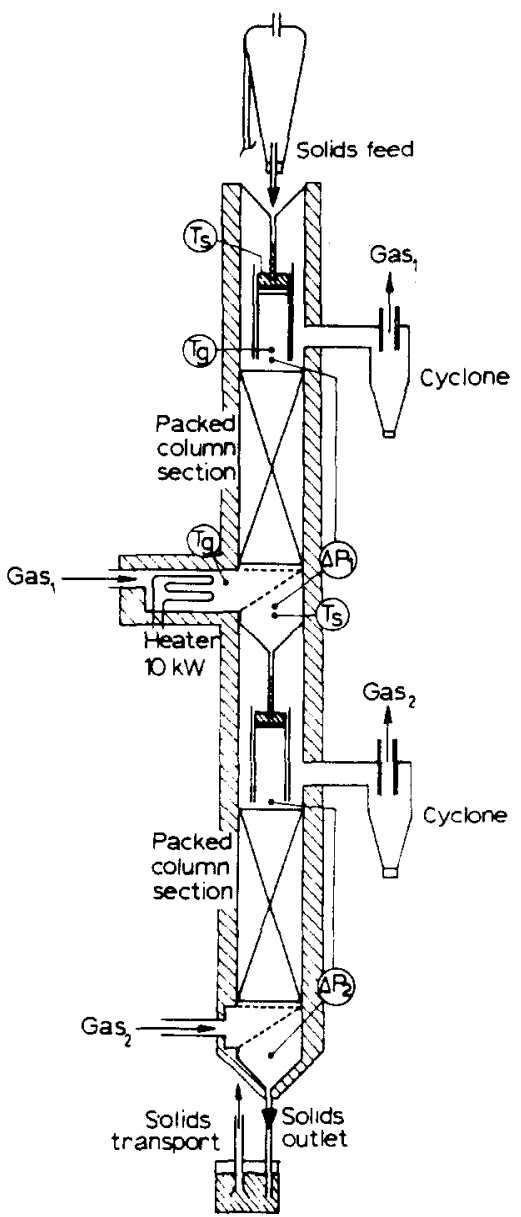

Fig. 2. Experimental apparatus.
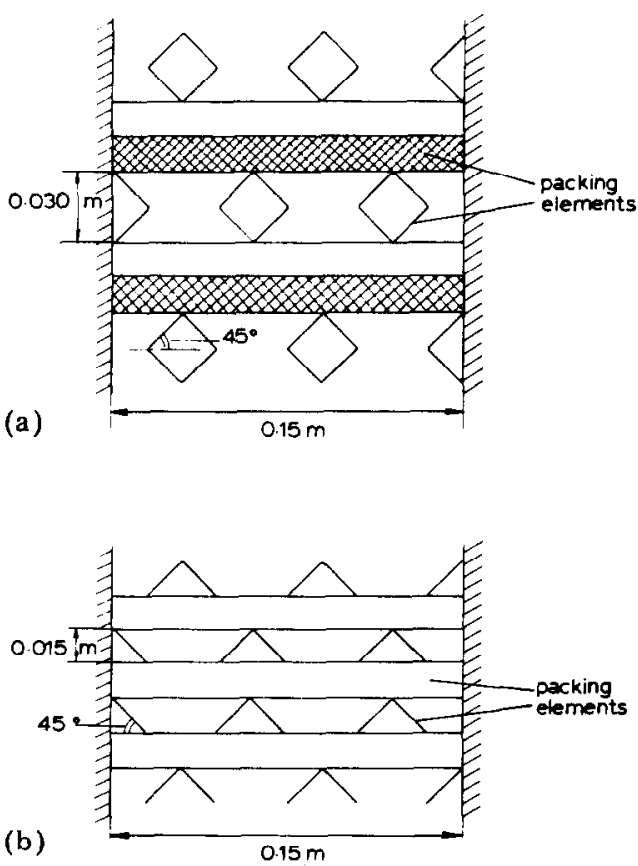

Fig. 3. Column packing constructions used in this work. (a), Packing A; (b), packing B. the air flow rate in the conveying line, while the mass flow rate was measured at the solids outlet of the lower column by diverting the solids stream to a vessel for some time and weighing the solid mass collected.

The pressure drop over the column was determined by means of pressure taps above the packing and below the gas distributor, connected to a micromanometer.

The inlet and outlet temperatures of both the gas and solids flows were measured by thermocouples. Solids-phase temperatures were determined either in the fluid bed seal, which can be assumed to be uniform in temperature, or by a thermocouple mounted in a collecting cup located below the gas distributor in the solids stream leaving the column. Below the gas distributor, a negligible gas flow exists and, therefore, only small temperature gradients are to be expected. This was confirmed by moving the collecting cup in radial directions. The solid particles used in the present study were sand particles with a mean particle diameter of $370 \times 10^{-6} \mathrm{~m}$. Other physical properties of these solids are summarized in Table 1.

TABLE 1

Physical properties of solid particles

\begin{tabular}{lc}
\hline Particle size distribution & \\
Diameter $\left(10^{-6} \mathrm{~m}\right)$ & Cumulative wt.\% \\
$<150$ & 0.0 \\
$<210$ & 0.6 \\
$<250$ & 2.9 \\
$<300$ & 17.7 \\
$<350$ & 37.5 \\
$<420$ & 58.6 \\
$<500$ & 95.6 \\
Mean particle diameter & $0.370 \times 10^{-3} \mathrm{~m}$ \\
Particle density & $2650 \mathrm{~kg} \mathrm{~m}^{-3}$ \\
Terminal velocity & $2.9 \mathrm{~m} \mathrm{~s}^{-1}$ \\
(in air, 293 K) & \\
\hline
\end{tabular}

a Assuming spherical shape

\section{RESULTS}

\section{Pressure drop}

Due to the flow resistance of the packing, a pressure drop $\Delta P_{0}$ is generated over the packed column. $\Delta P_{0}$ was measured at room temperature as a function of the gas mass flux. Results are shown in Fig. 4. For both packings, $\Delta P_{0} / L$ appears to be proportional 


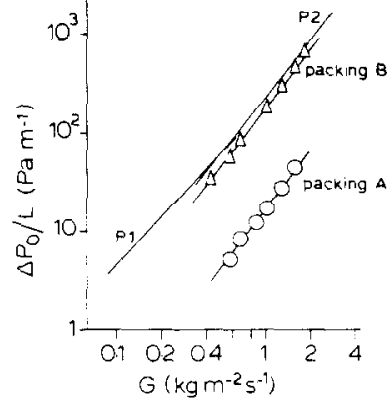

Fig. 4. Pressure drop over packing versus gas mass flux (at ambient conditions and solids flow absent). P1, $15 \times 15 \mathrm{~mm}$ Pall rings packing [11]; P2, $15 \times 15$ mm Pall rings packing [7].

to $G^{2.0}$. This is to be expected, because the Reynolds number of the gas flow around the packing elements is about $10^{3}$ at least and the gas flow can therefore be considered to be turbulent. The pressure drop is described as

$\frac{\Delta P_{0}}{L}=C_{\mathrm{D}, 0} \frac{\rho u_{0}^{2}}{2}$

From the experimental data shown in Fig. 4, the drag constant values are $C_{\mathrm{D}, 0}=38$ and $390 \mathrm{~m}^{-1}$ for packing $A$ and $B$ respectively. Previously, we have found for a packing similar to packing A a drag constant of $\mathbf{1 1 0}$ $\mathrm{m}^{-1}[1]$. Due to the larger tube diameter of the present packing, the surface area exposed in the direction of the gas flow is lower by a factor of 0.67 . This only partly explains the low value of $C_{\mathrm{D}, 0}$ for packing A. Apparently, the drag coefficient per unit surface area of the tubes is lower by a factor of about 0.5 .

As can be seen in Fig. 4, the packing constructed of square tubes (packing A) exhibits a much lower pressure drop than a packing of $15 \mathrm{~mm}$ Pall rings, as used by Large et al. [7] and Roes and van Swaaij [11]. The other packing (B) shows about the same resistance to flow. The higher value of $C_{\mathrm{D}, 0}$ observed for packing $B$, as compared with packing $A$, will be partly due to the higher projected surface area relative to the gas flow, but apparently also to the higher drag coefficient per unit surface area of the packing elements $C_{\mathrm{D}}$ of packing $\mathrm{B}$. For packings $\mathrm{A}$ and $\mathrm{B}, C_{\mathrm{D}}$ values of 2.3 and 11.7 respectively are obtained from

$C_{\mathrm{D}}=\frac{C_{\mathrm{D}, 0}}{A_{\mathrm{I}}}(A L)$
A value as low as 2.3 obtained for the square tubes in packing $\mathrm{A}$ is only little higher than the drag coefficient for turbulent gas flow around a single tube. For packing $\mathrm{B}$, however, the drag resistance is much higher, probably due to the denser structure of the packing and the poorly streamlined shape of the elements.

Apart from the pressure drop caused by the packing, an additional pressure drop is generated by the flow of solid particles. The net pressure drop caused by the solids flow, $\Delta P_{s}$, was calculated as

$\frac{\Delta P_{s}}{L}=\frac{\Delta P}{L}-\frac{\Delta P_{0}}{L}$

and the data thus obtained are presented in Fig. 5 as a function of the solids mass flux. It appears that $\Delta P_{\mathrm{s}} / L$ increases with the solids mass flux, because of an increasing solids hold-up. At low $S$, the increase in $\Delta P_{s} / L$ with $S$ is rather high, whereas at higher $S, \Delta P_{\mathrm{s}} / L$ becomes almost constant. In a study on the hydrodynamic behaviour of gas-solid trickle flow, we have demonstrated that at increasing solids mass flux the mean particle velocity may increase [1]. Therefore, the solids holdup may increase with $S$ less than proportionally and, accordingly, the net pressure

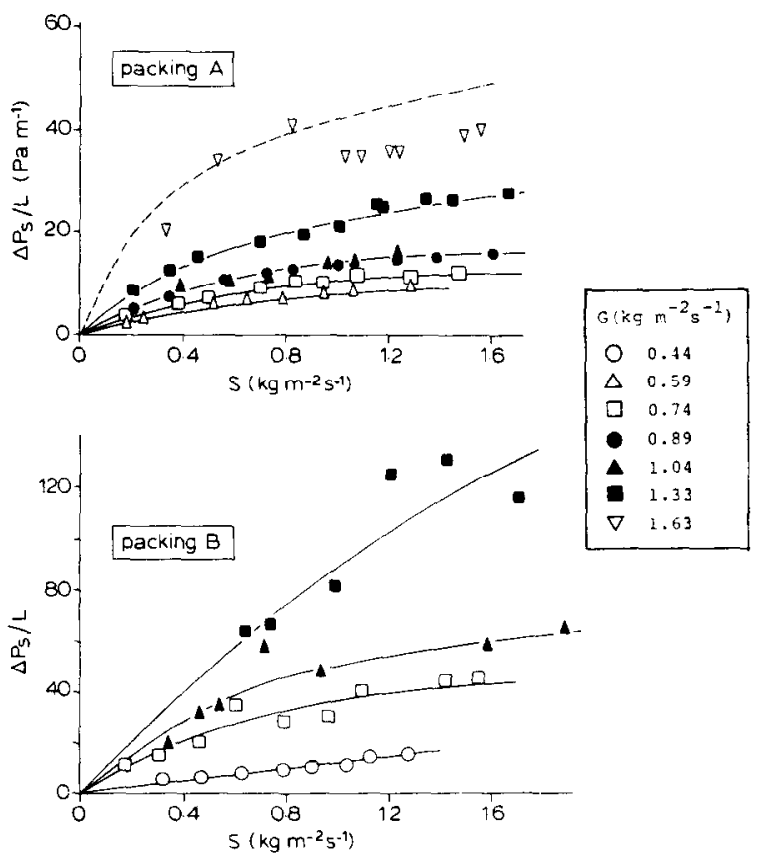

Fig. 5. Pressure drop caused by solids flow versus solids mass flux (at ambient conditions). Broken line, calculated curve for $\mathrm{G}=1.63 \mathrm{~kg} \cdot \mathrm{m}^{-2} \cdot \mathrm{s}^{-1}$, packing $A$. 
TABLE 2

Hydrodynamic data according to single-particle flow model [1]

\begin{tabular}{llll}
\hline $\begin{array}{l}G \\
\left(\mathrm{~kg} \mathrm{~m}^{-2} \mathrm{~s}^{-1}\right)\end{array}$ & $\begin{array}{l}u_{\mathrm{p}} \\
\left(\mathrm{m} \mathrm{s}^{-1}\right)\end{array}$ & $\begin{array}{l}\gamma_{\text {th }} \\
(-)\end{array}$ & $\begin{array}{l}\gamma_{\exp } \\
(-)\end{array}$ \\
\hline 0.59 & 0.251 & 0.26 & 0.23 \\
0.74 & 0.238 & 0.34 & 0.36 \\
0.89 & 0.223 & 0.43 & 0.40 \\
1.04 & 0.205 & 0.52 & 0.41 \\
1.33 & 0.161 & 0.71 & 0.6 \\
1.63 & 0.082 & 0.93 & 0.8 \\
\hline
\end{tabular}

Data used for calculations:

Solids: $\quad d_{\mathrm{p}}=0.37 \times 10^{-3} \mathrm{~m}, u_{\mathrm{t}}=2.9 \mathrm{~m} \mathrm{~s}^{-1}$

Packing: $\quad d=0.030 \mathrm{~m}, \epsilon_{0}=0.75$

Model data: $\quad u_{\mathrm{p}}(0)=-0.2 \mathrm{~m} \mathrm{~s}^{-1}, \epsilon=0.5$

drop caused by the solids may increase only moderately with $S$, particularly at higher mass fluxes. At very low $S$, single-particle flow behaviour will occur. Then, both the mean particle velocity $u_{\mathrm{p}}$ and the pressure drop caused by the solids can be derived from the hydrodynamic model presented elsewhere [1]. Some data obtained are given in Table 2. The pressure drop is given by the relative pressure drop $\gamma$, defined previously as [1]

$$
\begin{aligned}
\gamma & =\frac{\frac{\Delta P_{\mathrm{s}}}{L}}{\left(\frac{\Delta P_{\mathrm{s}}}{L}\right)_{\max }} \\
& =\frac{\Delta P_{\mathrm{s}} / L}{\beta \rho_{\mathrm{p}} \mathrm{g}}
\end{aligned}
$$

The lower the solids mass flux, the higher the value of $\gamma[1]$. So we derived experimental values for $\gamma$ from the pressure drop data (Fig. 5) at $S$ approaching zero. For the solids hold-up $\beta$, the following equation was used:

$\beta=\frac{S}{\epsilon_{0} \rho_{\mathrm{p}} u_{\mathrm{p}}}$

where $u_{\mathrm{p}}$ is the mean particle velocity calculated from the single-particle flow model. The agreement between $\gamma_{\text {exp }}$ thus calculated and $\gamma_{\text {th }}$ calculated from the single-particle flow model is fair, particularly at moderate gas mass fluxes. At high $G$, deviations are observed, but these are likely to be due to an increased inaccuracy in the determination of $\gamma_{\text {exp }}$. At high solids mass fluxes, $\gamma$ may decrease due to particle shielding occurring at higher solids hold-up [1]. As a typical example, we incorporated this effect by assuming for $\gamma$ the same relation as found for Sand 425 particles in the previous study [1]. Then, at $G=1.63 \mathrm{~kg} \mathrm{~m}^{-2} \mathrm{~s}^{-1}$, we could estimate $\Delta P_{s} / L$ as a function of $S$, which is represented in Fig. 5(a) by the broken line. As can be seen, the calculated curve fits the experimental data fairly well.

Comparing Figs. 5(a) and 5(b), it is clear that at given gas and solids mass fluxes, $\Delta P_{\mathrm{s}} / L$ is about 2 to 4 times higher over packing $B$ than over packing $A$. As the elements used in packing $B$ are only half as high as those used in packing $A$, the solids hold-up is likely to be higher by a factor of about 1.4 [1]. Furthermore, the denser packing structure might have caused a locally higher slip velocity and a more turbulent gas flow in packing $B$, increasing the drag resistance exerted by the gas on the solids flow and consequently the pressure drop $\Delta P_{s}$.

\section{Axial dispersion}

For the heat-transfer equations, we assumed that axial dispersion in both phases is negligible, i.e., that both phases are in plug flow. With regard to the gas phase, this could be realistic, as at high gas velocities the Bodenstein number (i.e., the dimensionless Peclet number related to the packing diameter) will amount to about 2.0 and so the $P e_{g}$ number of the column will be about 30 , corresponding to an essentially plug-flow behaviour. In the solids phase, however, axial dispersion might be substantially more important, particularly at low solids fluxes [12]. Therefore, we carried out some residence time distribution measurements in the solids phase. At room temperature, a tracer pulse of blackcoloured sand particles was injected into the solids feed of the lower column, while at the solids outlet the particles leaving the column were collected in a glass tube, from which the residence time distribution could be recorded by a reflectometer (see, for example, [12, 13]). The mean residence time $\tau_{\mathrm{s}}$ and the $P e_{\mathrm{s}}$ number were evaluated from the moments around the origin, using the boundary conditions of a closed-closed system [14]: 


\section{TABIE 3}

Results of residence time distribution measurements in solids phase (packing $\mathrm{B}$, ambient conditions)

\begin{tabular}{llll}
\hline $\begin{array}{l}G \\
\left(\mathrm{~kg} \mathrm{~m}^{-2} \mathrm{~s}^{-1}\right)\end{array}$ & $\begin{array}{l}S \\
\left(\mathrm{~kg} \mathrm{~m}^{-2} \mathrm{~s}^{-1}\right)\end{array}$ & $\begin{array}{l}P e_{\mathrm{s}} \\
(-)\end{array}$ & $\begin{array}{l}\tau_{\mathrm{s}} \\
(\mathrm{s})\end{array}$ \\
\hline 0.68 & 0.38 & 23 & 3.9 \\
& 0.57 & 17 & 3.2 \\
& 0.95 & 27 & 2.6 \\
0.89 & 1.31 & 56 & 3.3 \\
& 0.89 & 16 & 3.2 \\
& 1.04 & 22 & 3.0 \\
& 1.23 & 29 & 3.4 \\
1.11 & 1.48 & 31 & 3.1 \\
& 0.40 & 12 & 5.4 \\
& 0.50 & 12 & 4.8 \\
& 0.87 & 21 & 3.9 \\
\hline
\end{tabular}

$$
\begin{aligned}
\tau_{\mathrm{s}} & =M_{1} / M_{0} \\
& =\frac{\Sigma t_{i} c_{i} \Delta t_{i}}{\Sigma c_{i} \Delta t_{i}} \\
\sigma^{2} & =M_{2}\left(\frac{M_{0}}{M_{1}{ }^{2}}\right)-1 \\
& =\frac{2}{P e_{\mathrm{s}}}-\frac{2}{P e_{\mathrm{s}}{ }^{2}}\left[1-\exp \left(-P e_{\mathrm{s}}\right)\right]
\end{aligned}
$$

where $M_{0}, M_{1}$ and $M_{2}$ are zero, first and second moment around the origin respectively. The results of the RTD experiments are given in Table 3. From these data, it appears that at $S>1 \mathrm{~kg} \mathrm{~m}^{-2} \mathrm{~s}^{-1}$, the $P e_{\mathrm{s}}$ number is about 20 or more, which implies a close approximation to plug flow. For $S \approx$ $1 \mathrm{~kg} \mathrm{~m}^{-2} \mathrm{~s}^{-1}$, the gas-to-solids thermal capacity ratio, $C_{\mathrm{p}, \mathrm{g}} G /\left(C_{\mathrm{p}, \mathrm{s}} S\right)$, is close to unity. In this case, we can estimate the effect of axial dispersion on the overall performance of the column from

$$
\frac{1}{\mathrm{NTU}_{\mathrm{g}}}=\frac{1}{\mathrm{NTU}_{\text {true }}}+\frac{1}{P e_{\mathrm{g}}}+\frac{1}{P e_{\mathrm{s}}}
$$

where $N T U_{\text {true }}$ is the number of true interfacial transfer units. It was found in the course of the heat-transfer experiments described hereafter, that the axial dispersion terms would correspond to less than $20 \%$ of the overall performance at most. So for reasons of simplicity, we shall not incorporate axial dispersion effects as a separate factor in the calculations.

\section{Heat transfer}

From the inlet and outlet temperatures of both the gas and solids phases, the heattransfer rate constant was evaluated by the numerical calculation procedure. The value of the heat-loss rate constant $U_{\mathrm{L}} a_{\mathrm{L}}$ was determined at zero solids flux, using eqn. (6), and was found to be about $0.2 \mathrm{~kW} \mathrm{~m} \mathrm{~m}^{-3} \mathrm{~K}^{-1}$. Therefore, for $G \geqslant 0.59 \mathrm{~kg} \mathrm{~m}^{-2} \mathrm{~s}^{-1}$, the heat losses from the apparatus would amount up to about $10 \%$ of the thermal energy of the hot gas fed to the column.

Data on thermal properties of gas and solids were gathered from the literature [15]. For $C_{p, s}$ the data given for $\alpha$-quartz $\left(\mathrm{SiO}_{2}\right)$ were used, which could be fitted by

$C_{\mathrm{p}, \mathrm{s}}=1.69-16.3 \times T^{-0.5}$

where $T$ is given in kelvins. For each experiment, we checked the heat balance over the column and it was found that for low solids mass fluxes, i.e., up to about $0.5 \mathrm{~kg} \mathrm{~m}^{-2} \mathrm{~s}^{-1}$, deviations were always less than $5 \%$. At higher $S$, the thermal energy ratio of outlet to inlet flows tended to values slightly above 1.0 , probably due to an overestimation of $C_{p, s}$. By applying a somewhat different equation for $C_{p, s}$ (in [15], eqn. (3-37)), which gives $C_{\mathrm{p}, \mathrm{s}}$ values 5 to $10 \%$ lower than those of eqn. (16), deviations of the heat balance became less than about $10 \%$.

The experimental results on the heattransfer rate constant $\alpha a$ are presented in Fig. 6. As could be expected, $\alpha a$ increases with the solids mass flux and with the gas mass flux. At low solids mass fluxes, however, $\alpha a$ increases rather rapidly, whereas at higher $S$ it increases only slowly with increasing $S$, particularly in the case of packing A (Fig. 6(a)). As in the case of the pressure drop $\Delta P_{\mathrm{s}}$ (see Fig. 5), this might be due to the increase in mean particle velocity, causing a less than proportional increase of the solids hold-up with solids mass flux. At low $S$, the mean particle velocity follows from the single-particle flow model [1]. However, in the heat-transfer experiments, a temperature gradient exists in the column, which will influence the gas-flow properties. At given gas mass flux, the superficial gas velocity depends on temperature and so the mean particle velocity is expected to decrease with increasing temperature due to the increasing drag resistance exerted by the gas flow. The temperature gradient over the 

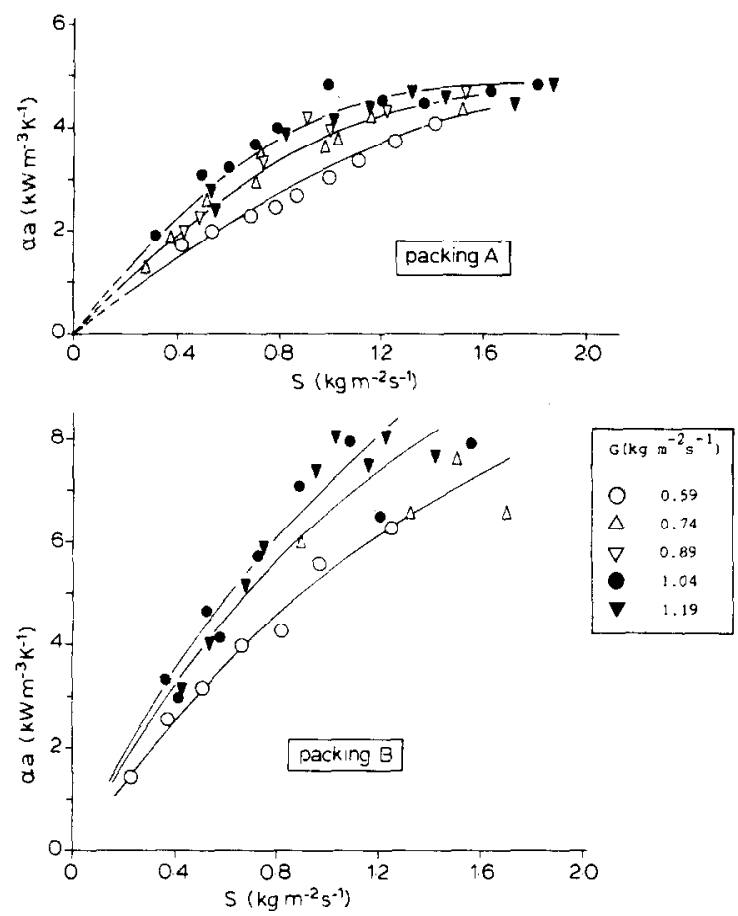

Fig. 6. Experimental data on heat-transfer rate constant versus solids mass flux as calculated using the numerical model.

column thus affects the local mean particle velocity and, accordingly, the local solids hold-up. We calculated a gas temperature profile over the column from the numerical calculation of the heat-transfer rate constant. From this, the local values of the mean particle velocity were obtained according to the particle flow model [1]. The local value of the solids surface area, which is likely to determine the heat-transfer area, was then determined from

$$
\begin{aligned}
a_{s} & =\frac{6}{d_{\mathrm{p}}} \beta \epsilon_{0} \\
& =\frac{6 S}{\rho_{\mathrm{p}} d_{\mathrm{p}}} \frac{1}{u_{\mathrm{p}}}
\end{aligned}
$$

As shown in Fig. 7 , at $G=0.74 \mathrm{~kg} \mathrm{~m}^{-2} \mathrm{~s}^{-1}$, $a_{\mathrm{s}}$ would be approximately constant, even at high $S$ where maximum temperature gradients are encountered. The small effect of temperature on the solids surface area is due to the fact that the local gas velocity is always well below the terminal velocity of the particles. At higher $G$ and/or higher gas inlet temperatures, the solids hold-up profile may substantially change, as will be discussed later. For
$G \leqslant 0.74 \mathrm{~kg} \mathrm{~m}^{-2} \mathrm{~s}^{-1}$ and $T_{\mathrm{g}, \text { in }}=250^{\circ} \mathrm{C}$, how ever, $a_{\mathrm{s}}$ could be assumed to be constant and we would estimate the solids surface area by the average value of $a_{\mathrm{s}}$. The heat-transfer rate constant $\alpha a$ depends not only on the solids surface area, but also on the heattransfer coefficient $\alpha$. Many heat-transport phenomena may contribute to the average value of $\alpha$, such as convective and radiative heat transfer from gas to solids and from the packing elements to the solids flow. However, it seems reasonable to assume that convective heat transfer from gas to solids would be the most important one. Heat transfer via the packing could not have a significant effect on the overall heat-transfer rate from gas to solids, because of the relatively small number of collisions and the extremely short contact times of the solids with the packing. Moreover, the heat-transfer coefficient for radiation is at least a factor of $\mathbf{1 0}$ lower than the convective heat-transfer coefficient around the solid particles, due to the rather low temperature level. Therefore, the heat-transfer coefficient $\alpha$ could be estimated by the heattransfer coefficient given by the NusseltReynolds relationship for a single sphere [16]:

$N u=\frac{\alpha_{\mathrm{s}} d_{\mathrm{p}}}{\lambda}=2.0+0.60 \operatorname{Re}^{0.50} \mathrm{Pr}^{0.33}$

where $R e$ is related to the mean particle slip velocity. It was checked that under the experimental conditions, heat conduction in the particles would not offer any significant

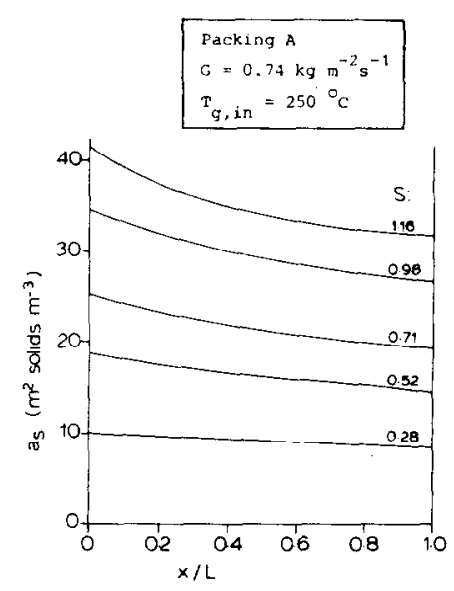

Fig. 7. Specific solids surface area calculated from the single-particle flow model [1] as a function of position in column (temperature profile according to heat-transfer calculation model). Packing A. 
TABLE 4

Comparison of experimental and calculated heat-transfer data (packing $\mathrm{A}, G=0.74 \mathrm{~kg} \cdot \mathrm{m}^{-2} \cdot \mathrm{s}^{-1}, T_{\mathrm{g}, \text { in }}=250{ }^{\circ} \mathrm{C}$ )

\begin{tabular}{|c|c|c|c|c|c|}
\hline $\begin{array}{l}S \\
\left(\mathrm{~kg} \mathrm{~m}^{-2} \mathrm{~s}^{-1}\right)\end{array}$ & $\begin{array}{l}a_{\mathrm{s}} \\
\left(\left(\mathrm{m}^{2} \text { solids }\right) \mathrm{m}^{-3}\right)\end{array}$ & $\begin{array}{l}\overline{\alpha_{\mathrm{s}} a_{s}} \\
\left(\mathrm{~W} \mathrm{~m}^{-3} \mathrm{~K}^{-1}\right)\end{array}$ & $\begin{array}{l}\alpha a_{\exp } \\
\left(W_{m^{-3}} K^{-1}\right)\end{array}$ & $\frac{\alpha a_{\text {exp }}}{\widetilde{\alpha_{s} a_{s}}}$ & 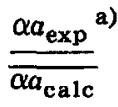 \\
\hline 0.28 & 9.3 & 4500 & 1270 & 0.28 & 0.32 \\
\hline 0.38 & 12.4 & 5900 & 1830 & 0.31 & 0.37 \\
\hline 0.52 & 16.5 & 7700 & 2570 & 0.33 & 0.40 \\
\hline 0.71 & 21.9 & 10100 & 2940 & 0.29 & 0.38 \\
\hline 0.73 & 22.4 & 10200 & 3500 & 0.34 & 0.44 \\
\hline 0.98 & 29.8 & 13600 & 3620 & 0.27 & 0.36 \\
\hline 1.03 & 31.1 & 14200 & 3760 & 0.27 & 0.36 \\
\hline 1.16 & 34.7 & 15700 & 4200 & 0.27 & 0.37 \\
\hline
\end{tabular}

a) $a$ in $\alpha a_{\text {calc }}$ corrected for the actual increase in $u_{\mathrm{p}}$ (data from [1]; Sand 425,G=0.85 $\mathrm{kg} \mathrm{m}^{-2} \mathrm{~s}^{-1}$ ))

resistance to the overall gas-to-solids heattransfer rate, as the Biot number (defined as $\left.\alpha_{\mathrm{s}} d_{\mathrm{p}} / \lambda_{\mathrm{p}}\right)$ is always less than 0.1 .

The values of $\alpha a$ obtained from the heattransfer coefficient $\alpha_{\mathrm{s}}$ and the solids surface area $a_{\mathrm{s}}$ are given in Table 4 as $\overline{\alpha_{s} a_{\mathrm{s}}}$. The experimental values of $\alpha a$ appear to be about a factor of 3 lower than $\overline{\alpha_{s} a_{s}}$, which would suggest an actually lower heat-transfer coefficient or a lower effective solids surface area. At increasing $S$, a slight decrease of $\alpha a_{\exp } \sqrt{\alpha_{\mathrm{s}} a_{\mathrm{s}}}$ can be observed. This could have been caused by an increase in mean particle velocity at increasing solids mass flux. In previous experiments on a similar gassolids system, we observed that the mean particle velocity could become higher by, for example, a factor of 1.5 at solids mass fluxes of $2.0 \mathrm{~kg} \mathrm{~m}^{-2} \mathrm{~s}^{-1}$, compared with the singleparticle velocity at $S \approx 0$ (cf. [1], the data for Sand 425 particles). Assuming such an effect of $S$ on the mean particle velocity, we could correct the data of $\overline{\alpha_{s} a_{s}}$ for the influence of $S$ on the solids surface area. The data on $\alpha a_{\exp } \sqrt{\alpha a_{\text {calc }}}$ thus obtained appear to be fairly constant (see Table 4), implying that there is a close relation between the experimental value of the heat-transfer rate constant and the solids surface area available. The fact of $\alpha a_{\text {exp }}$ still amounting to about 35 to $40 \%$ of $\overline{\alpha a_{\text {calc }}}$ can be explained from the solids being partly in the wake of the packing, i.e., the region just above the packing elements, where both the heat-transfer coefficient $\alpha_{\mathrm{s}}$ and the solids surface area effective in heat transfer could be lower.

According to the above description of the gas-solid heat transfer, an increase in $\alpha a$ is to be expected at higher gas mass fluxes and at higher gas temperatures. For single-particle flow, an increase in $a$ should be observed, particularly in the lower, high-temperature region of the column. This could lead to the situation where $u_{\mathrm{p}}$ becomes zero, i.e., the particles are not able to pass the hot zone (Fig. 8). However, in the case of a high solids concentration, single-particle flow is not likely and, due to agglomeration of solids into trickles, a higher slip velocity will be attained, again allowing downflow of solids. Nevertheless, a higher value of $\alpha a$ should be effected both by a higher gas mass flux and a higher gas inlet temperature. As shown above (Fig. 6), $\alpha a$ increases with gas mass flux. An increase in temperature, too, results in slightly higher values of $\alpha a$, as can be seen in Fig. 9.

From the experimental data on $\alpha a$ presented in Figs. 6 and 9, it is apparent that $\alpha a$ is about $50 \%$ higher over packing $B$ than over packing $A$. This can be partly explained by a higher solids hold-up due to the lower height of the packing elements, but obviously heattransfer performance is increased further, probably owing to the denser structure of packing B. It is noteworthy that similar differences between both packings were encountered before with regard to the pressure drop caused by the solids flow.

In Fig. 10, the number of overall heattransfer units $\left(\mathrm{NTU}_{\mathrm{g}}\right)$ is presented, as these were calculated from the heat-transfer rate constant data using eqn. (7). At increasing solids mass flux, $\mathrm{NTU}_{\mathrm{g}}$ increases rapidly, particularly in the case of packing B. An increase in gas mass flux, however, usually 

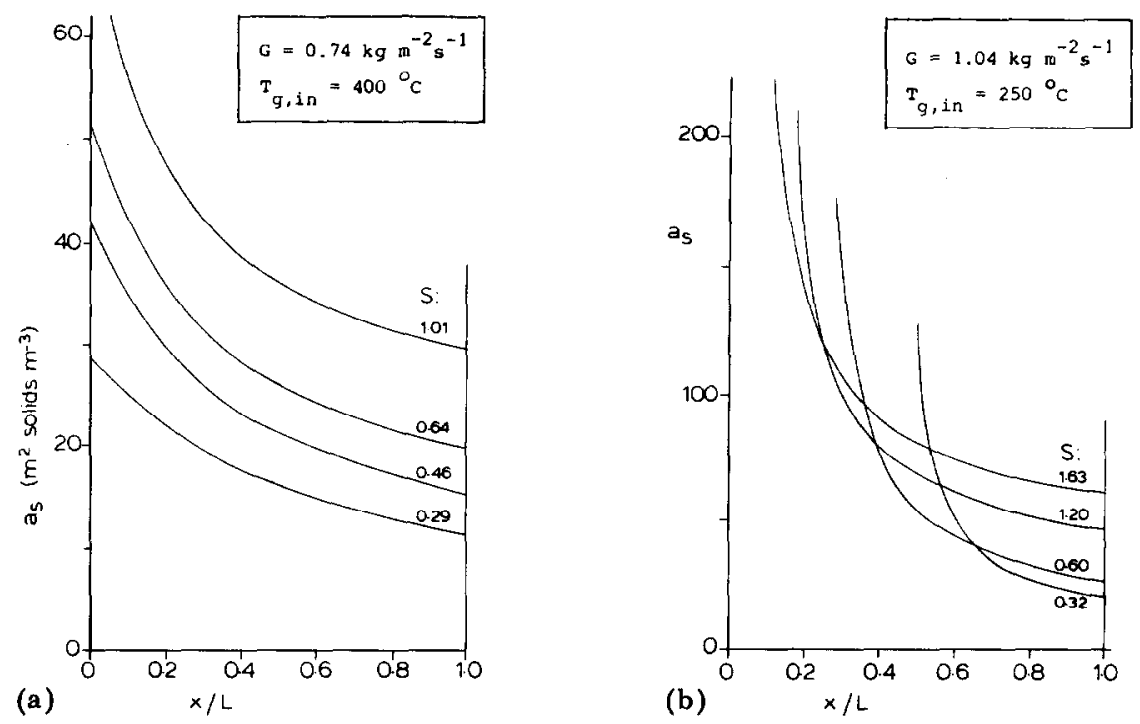

Fig. 8. Calculated specific solids surface area. (a), For a gas inlet temperature of $400{ }^{\circ} \mathrm{C}$; (b) for $G=1.04$ $\mathrm{kg} \mathrm{m}^{-2} \mathrm{~s}^{-1}$.

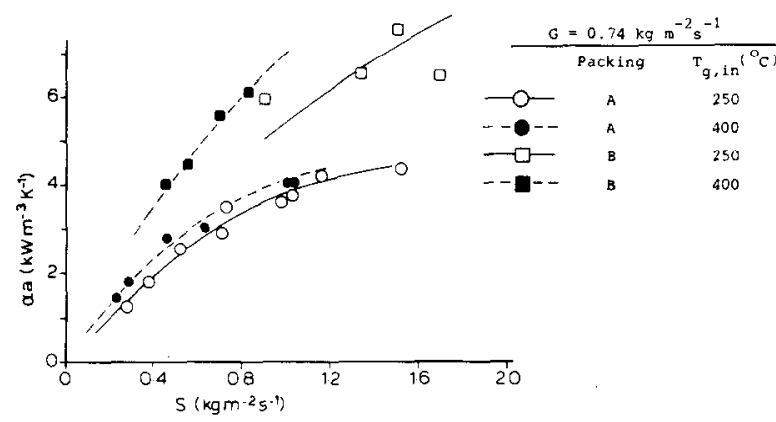

Fig. 9. Experimental data on heat-transfer rate constant versus solids mass flux at gas inlet temperatures of 250 and $400{ }^{\circ} \mathrm{C}$ respectively.

results in lower $\mathrm{NTU}_{\mathrm{g}}$ values. It appears that packing $B$ would be attractive for heattransfer applications because of the rather high values of $\mathrm{NTU}_{\mathrm{g}}$ observed, i.e., about 3 to 4 for a solids mass flux of about $1 \mathrm{~kg} \mathrm{~m}^{-2} \mathrm{~s}^{-1}$ and a packing height of $0.5 \mathrm{~m}$. On the other hand, the much lower pressure drop over packing $A$, being about 10 to $20 \%$ of that over packing $B$, might be important in view of special applications such as off-gas waste heat recovery.

\section{CONCLUSIONS}

The heat-transfer performance of the gassolid trickle flow column clearly depends on the gas and solids mass fluxes and on the type of packing construction used. The overall heat-transfer rate constant is affected only
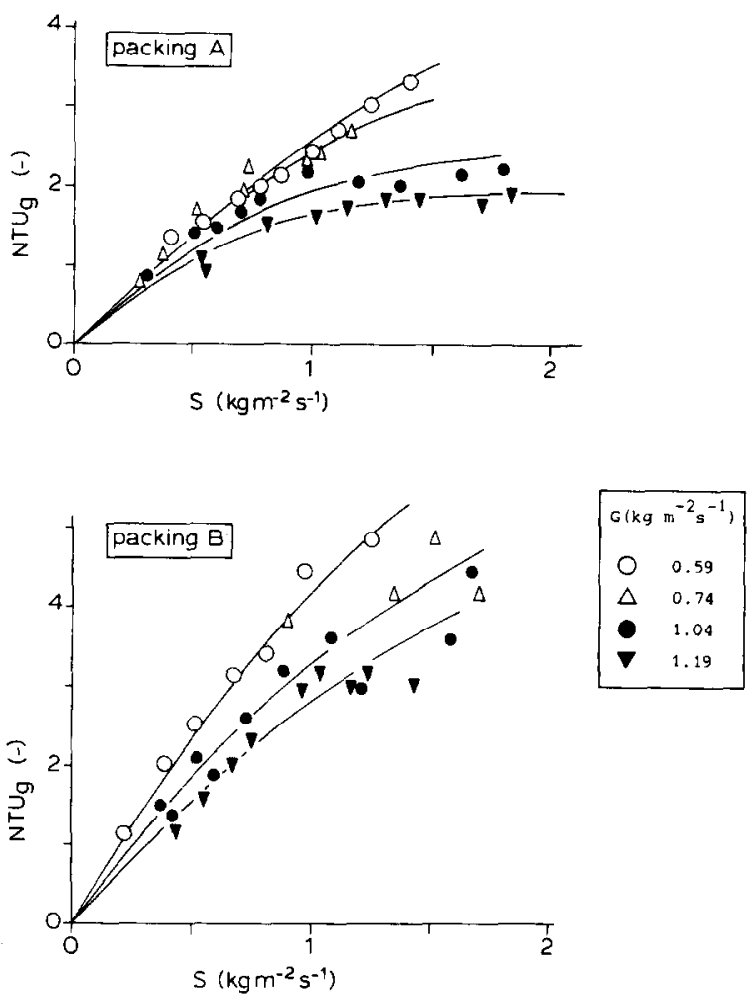

Fig. 10. Number of overall heat-transfer units; measurements interpreted using numerical model. Packing height $0.48 \mathrm{~m}$.

slightly by axial dispersion in the solids phase and the gas phase, and it can be correlated to the heat-transfer coefficient around the solid particles and the solids surface area available for heat transfer. As in the case of the pressure drop caused by the solids flow, the heat- 
transfer rate constant is mainly determined by single-particle flow behaviour, at low solids mass fluxes. At higher solids mass fluxes, i.e., at higher solids hold-up, heat transfer becomes affected by agglomeration effects in the solids phase as these increase the mean particle velocity at a given gas mass flux.

\section{LIST OF SYMBOLS}

$a_{\mathrm{s}}$

A

$A_{\mathrm{f}}$

$c_{\mathrm{i}}$

$C_{\mathrm{D}}$

$C_{\mathrm{D}, 0}$

$C_{\mathrm{p}}$

$d_{\mathrm{p}}$

g

G

HTU

$L$

$M_{0}, M_{1}, M_{2}$

$n$

$\mathrm{NTU}_{\mathrm{g}}$

$\mathrm{NTU}_{\text {true }}$

$\mathrm{Nu}$

$\Delta P$

$\Delta P_{0}$

$\Delta P_{\mathrm{s}}$

$P e$

$\mathrm{Pr}$

Re

$S$

$t$

$T$

$T_{0}$

$\Delta T$

$u_{0}$

$u_{\mathrm{p}}$

specific surface area of the solids, $\left(\mathrm{m}^{2}\right.$ solids $)\left(\mathrm{m}^{3}\right.$ column $)^{-1}$

cross-sectional area of column, $\mathrm{m}^{2}$

packing surface area in direc-

tion of gas flow, $\mathrm{m}^{2}$

tracer concentration in RTD

signal, - (arbitrary units)

drag coefficient of packing

elements, -

drag constant of packing, $\mathrm{m}^{-1}$

specific heat, $\mathrm{kJ}_{\mathrm{kg}}{ }^{-1}{ }^{\circ} \mathrm{C}^{-1}$

mean particle diameter, $\mathrm{m}$

acceleration due to gravity, $\mathrm{m} \mathrm{s}^{-2}$

gas mass flux, $\mathrm{kg} \mathrm{m}^{-2} \mathrm{~s}^{-1}$

height of an overall heat-

transfer unit, $m$

height of packing, $m$

moments around origin, -

number of calculation steps, -

number of overall heat-

transfer units, -

number of true heat-transfer

units, -

Nusselt number, -

pressure drop over column, $\mathrm{Pa}$

pressure drop over packing, $\mathrm{Pa}$

pressure drop caused by solids

flow, $\mathrm{Pa}$

Peclet number, -

Prandtl number, -

Reynolds number, -

solids mass flux, $\mathrm{kg} \mathrm{m}^{-2} \mathrm{~s}^{-1}$

time, $s$

temperature, ${ }^{\circ} \mathrm{C}$

temperature of surroundings, ${ }^{\circ} \mathrm{C}$ temperature change over column, ${ }^{\circ} \mathrm{C}$ mean particle velocity, $\mathrm{m} \mathrm{s}^{-1}$
$U_{\mathrm{L}} a_{\mathrm{L}}$

$x$

$\Delta x$

\section{Greek symbols}

$\alpha$

$\alpha a$

$\beta$

$\gamma$

$\epsilon_{0}$

$\lambda$

$\lambda_{\mathrm{p}}$

$\rho$

$\rho_{\mathbf{p}}$

$\sigma^{2}$

$\tau_{\mathrm{s}}$

\section{Subscripts}

calc

$\exp$

g

in

$\max$

out

s

th

\section{REFERENCES}

1 A. B. Verver and W. P. M. van Swaaij, Powder Technol., 45 (1985)

2 A. W.M. Roes, Ph.D. Thesis, Twente University of Technology, Enschede, The Netherlands (1978). heat-transfer coefficient, $\mathrm{kW}$ $\mathrm{m}^{-2}{ }^{\circ} \mathrm{C}^{-1}$

heat-transfer rate constant, $\mathrm{kW} \mathrm{m}^{-3}{ }^{\circ} \mathrm{C}^{-1}$

single-particle heat-transfer coefficient, $\mathrm{kW}\left(\mathrm{m}^{2} \text { solids) }\right)^{-1}$ ${ }^{\circ} \mathrm{C}^{-1}$

calculated heat-transfer rate constant (for single-particle flow), $\mathrm{kW} \mathrm{m}{ }^{-3}{ }^{\circ} \mathrm{C}^{-1}$

calculated heat transfer coefficient (corrected for an in-

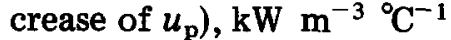
solids hold-up, ( $\mathrm{m}^{3}$ solids) $\left(\mathrm{m}^{3} \text { void }\right)^{-1}$

relative pressure drop of the solids (see eqn. (11)), packing void fraction, $\left(\mathrm{m}^{3}\right.$ void) $\left(\mathrm{m}^{3} \text { column }\right)^{-1}$

thermal conductivity of gas, $\mathrm{kW} \mathrm{m} \mathrm{m}^{-1}{ }^{\circ} \mathrm{C}^{-1}$

thermal conductivity of solid particles, $\mathrm{kW} \mathrm{m} \mathrm{m}^{-1}{ }^{\circ} \mathrm{C}^{-1}$

density of gas, $\mathrm{kg} \mathrm{m}^{-3}$

density of solid particles, $\mathrm{kg} \mathrm{m^{-3 }}$

variance of RTD curve, mean residence time of solid particles, $\mathbf{s}$

calculated value experimental value refers to gas flow at inlet theoretically maximum value at outlet refers to solids flow according to theory superficial gas velocity, $\mathrm{m} \mathrm{s}^{-1}$ 
3 A. W. M. Roes and W. P. M. van Swaaij, Chem. Eng. J., 18 (1979) 29.

4 I. W. Noordergraaf, A. W. M. Roes and W. P. M. van Swaaij, Proc. 3rd Int. Conf. Fluidization, New Hampshire, USA, 1980.

5 J. H. Mannon, Chem. Eng., 88 (1981), March 23, 79.

6 St. Gobain Industries, Fr. Pat. $1469109,1965$.

7 J. F. Large, M. Naud, P. Guigon and M. A. Bergougnou, Chem. Eng. J., 22 (1981) 95.

8 J. F. Large, P. Guigon and E. Saatdjian, Prepr. 4th Int. Conf. Fluidization, Kashikojima, Japan, 1983.

9 M. S. Sagoo, J. Heat Recovery Syst., 1 (1981) 133.
10 M. S. Sagoo, J. Heat Recovery Syst., 2 (1982) 23.

11 A. W. M. Roes and W. P. M. van Swaaij, Chem. Eng. J., 17 (1979) 81.

12 A. W. M. Roes and W. P. M. van Swaaij, Chem. Eng. J., 18 (1979) 13.

13 A. B. Verver, Ph.D. Thesis, Twente University of Technology, Enschede, The Netherlands (1984).

14 E. T. van der Laan, Chem. Eng. Sci., 7 (1958) 187.

15 R. H. Perry and C. H. Chilton, Chemical Engineers' Handbook, McGraw-Hill, New York, 5th edn., 1973.

16 R. B. Bird, W. E. Stewart and E. N. Lightfoot, Transport Phenomena, Wiley, New York, 1960. 